\title{
Effects of different polishing systems on the surface roughness and microhardness of a silorane-based composite
}

\author{
Vanessa C Ruschel ${ }^{1,2^{*}}$, Gabriela R Basso ${ }^{3,4}$, Mauro AC de Andrada ${ }^{1,2}$ and Hamilton P Maia ${ }^{1,2^{*}}$
}

\footnotetext{
* Correspondence: ruschelvc@gmail. com; maiahp@ccs.ufsc.br

${ }^{1}$ Department of Dentistry, Federal University of Santa Catarina,

Florianópolis, Santa Catarina, Brazil

Full list of author information is

available at the end of the article
}

\begin{abstract}
The current study investigated the effects of different polishing systems on the surface roughness and microhardness of a silorane-based resin composite. Forty disks were fabricated $(\varnothing=12 \mathrm{~mm}, h=2.5 \mathrm{~mm}$ ) of Filtek P90 (3 M ESPE, USA). The specimens were divided into four groups $(n=10)$, according to the polishing system: G1 - Mylar strip (control); G2 - Felt-disc + diamond paste, G3 - Sandpaper discs; $\mathrm{G} 4$ - Silicone tips. The specimens were stored in distilled water at $37^{\circ} \mathrm{C}$ for $24 \mathrm{~h}$. The external surface roughness was determined through measuring the $R_{a}$ of the specimens. The Vickers microhardness was measured using a microhardness tester. The values of surface roughness and microhardness of each specimen were statistically analyzed using one-way ANOVA, Games-Howell and Ryan-Einot-Gabriel-Welsch (REGW-Q), and setting the statistical significance at $p \leq 0.05$. It was observed that G2 $(0.42 \mu \mathrm{m})$ and $\mathrm{G} 4(0.43 \mu \mathrm{m})$ showed statistically significant differences when compared to groups $\mathrm{G} 1(0.25 \mu \mathrm{m})$ and $\mathrm{G} 3(0.19 \mu \mathrm{m})(\mathrm{p}<0.05)$. There was no statistical difference between groups regarding microhardness $(p>0.05)$. The polishing systems altered the surface roughness of a silorane-based resin composite, but did not influence the microhardness values.
\end{abstract}

Keywords: Composite resins; Dental materials; Dental polishing; Surface properties; Permanent dental restoration

\section{Background}

The microhardness and surface roughness are properties of a composite that are related to the material's resistance to masticatory forces, its appearance such brightness and surface texture and the longevity of the restoration. The finishing and polishing procedure may influence these properties of a composite. With the results of this article, the authors related that the polishing systems altered the surface roughness of a silorane-based resin composite, but did not influence its microhardness.

\section{Introduction}

A silorane-based resin matrix presents less curing shrinkage when compared to a methacrylate resin matrix. The silorane is chemically composed of oxirane and siloxane molecules. The siloxane gives the material the property of hydrophobicity, while oxiranes are rings which act chemically during formation of polimers through a 
cationic ring-opening mechanism. This process results in polymerization shrinkage of less than 1\% [1]. A low volume contraction of the material lessens the stress generated at the adhesive bond and, consequently, reduces the incidence of microleakage, secondary caries, postoperative sensitivity, enamel fractures, and improves the marginal adaptation of restorations [2-4]. The silorane-based resin has physical, biologhical and mechanical properties that are clinically acceptable and perform either similarly [5-8] or superiorly [9-12] to methacrylate-based resins.

The surface roughness of a restorative material influences the aesthetic appearance of a restoration in terms of brightness and texture [13]. An increased surface roughness allows for the accumulation of plaque, increasing the occurrence of recurrent caries [14]. The step of finishing and polishing composite restorations aims to provide adequate occlusal anatomy, remove small excesses and get a smooth, flawless surface that allows for adequate light reflection [15]. The surface roughness depends on various factors, such as: the amount and size of the filler particles, the type of resin matrix, and the type and particle size of the abrasives. Larger filler particles in a material protrude from the surface; as the resin matrix is removed during the finishing and polishing, the arithmetic average roughness values $\left(R_{a}\right)$ tend to increase [16,17]. According to Marghalani (2010) [18], the surface smoothness obtained in silorane-based composite was greater than or equal to the smoothness obtained with methacrylate-based resins.

The mechanical properties of a composite, such as hardness and flexural strength, are fundamental to the material in resisting masticatory forces and providing greater longevity. The microhardness of a composite is directly related to the depth of cure of the restorative material. A lower microhardness of a resin composite indicates that the material is more susceptible to scratches and surface defects that can reduce the materials flexural strength and cause premature failure of the restoration $[19,20]$. Thus, the purpose of this current study is to evaluate the effect of different polishing systems on the surface roughness and hardness of a silorane-based resin composite.

\section{Methods}

Forty disks were fabricated using a silorane-based resin composite (Filtek P90, 3 M ESPE, St Paul, MN, USA) (Table 1). The internal mold of a metal matrix ( $\varnothing=12 \mathrm{~mm}, h=2.5 \mathrm{~mm}$ ) was filled with the composite in one increment. A mylar strip was placed on top of the uncured composite. A glass slide (1.1 mm thick) was applied on top of the mylar strip and pressure applied to remove excess resin. The composite was light-cured on both sides of the disks according to the manufacturer's instructions, using an LED light-curing unit (Translux Blue - Heraeus Kulzer, South Bend, USA) with a light intensity of $876 \mathrm{~mW} / \mathrm{cm}^{2}$. The specimens were stored in distilled water at $37^{\circ} \mathrm{C}$ for $24 \mathrm{~h}$, and divided into four groups $(\mathrm{n}=10)$ according to the polishing system used. In group $\mathrm{G1}$, no polishing was performed (control). In groups G2, G3 and G4, the specimens were individually coupled to a metallic circular matrix and polished with $\mathrm{SiC}$ sandpaper (\#1200) for $5 \mathrm{~s}$ to remove the outer resin layer, obtain a standardized and stable surface. Then, the

Table 1 Composition of the resin composite

\begin{tabular}{lllllll}
\hline Material & Shade & Filler & Filler-size & Matrix & $\begin{array}{l}\text { Filler } \\
\text { (wt \%) }\end{array}$ & Manufacturer \\
\hline Filtek P90 & A3 & $\begin{array}{l}\text { Quartz and } \\
\text { yttrium fluoride }\end{array}$ & $47 \mu \mathrm{m}$ & $\begin{array}{l}\text { Silorane } \\
\text { (oxirane and siloxane) }\end{array}$ & 76 & 3 M ESPE, St \\
& & & & Paul/MN, USA \\
\hline
\end{tabular}


specimens were submitted to differing polishing procedures: G2 - felt disc and diamond paste (Diamond Flex and DiamondExcel, FGM, Joinville, SC, Brazil), G3 - Sandpaper discs with sequential granulation: coarse, medium, fine and extra-fine (Diamond Pro, FGM, Joinville, SC, Brazil) and G4 - Silicone tips with two different granulations (DFL polishers, DFL, Rio de Janeiro, RJ, Brazil) (Table 2). The polishing systems are described in Table 3.

The time of polishing with each instrument was standardized at $30 \mathrm{~s}$. The pressure exerted on the surface of the composite was intermittent and controlled by the operator. The silicone tips were used in a low-speed contra-angle handpiece and under water cooling, according to the manufacturer's recommendations. The felt discs and sandpaper discs were also used at low speed, but without water cooling. After the use of each instrument, the specimens were rinsed with water spray for $15 \mathrm{~s}$ to remove debris.

Prior to measuring the surface profile, the specimens were stored in distilled water at $37^{\circ} \mathrm{C}$ for $24 \mathrm{~h}$. The evaluation of surface roughness was performed on all 10 specimens of each group instrument using a Surface Roughness Digital Portable Tester (RP-100, Instrutherm, São Paulo, Brazil). The Surface Roughness Tester was operated with a cut-off of $0.8 \mathrm{~mm}$, a reading speed of $0.1 \mathrm{~mm} / \mathrm{s}$ and a measurement distance of $4 \mathrm{~mm}$, according to the JIS (Japan Industrial Standard B 0601, 1994). The specimens were placed in a metal device so that the polished surface was facing upwards and parallel to the base of the Surface Roughness Tester. There were three measurements in different areas of each specimen and the individual average value was used for statistical analysis.

Vickers microhardness number (VHN) was evaluated using a microhardness tester (HMV 21.23 version - Shimadzu Corp., Kyoto, Japan) with a $500 \mathrm{~g}$ load applied for 15 seconds. The specimens were individually positioned perpendicularly to the tester tip, and the VHN values were recorded by a software program (CAMSTM_WIN program - Newage Testing Instruments, Southampton, PA, USA). In each sample, three indentations at different points were recorded, and the average microhardness value was calculated.

Representative specimens from each group were observed by scanning electron microscopy (SEM). Following sputter gold coating, the surface morphology of the specimens was observed under $500 \times$ magnification.

Data were submitted to the Levene normality test. Surface roughness $\left(R_{a}\right)$ and Microhardness $(\mathrm{VHN})$ variations were evaluated by one-way ANOVA at a significance level of $5 \%(\mathrm{p} \leq 0.05)$. The Welch adjustment for the ANOVA and the post hoc GamesHowell test was used to evaluate the surface roughness. The post hoc Ryan-EinotGabriel-Welsch (REGW-Q) was used to evaluate the microhardness test.

\section{Results}

The $R_{a}$ values were statistically similar between groups G2 and G4, and both were significantly when compared to G1 and G3 $(\mathrm{p}<0.05)$. Also, these two other groups

Table 2 Groups according to the polishing system utilized

\begin{tabular}{llll}
\hline Group & Polishing procedure & \multicolumn{2}{c}{ Specimen distribution } \\
\cline { 3 - 4 } & & Roughness and microhardness & SEM \\
\hline G1 & Mylar strip (control) & 10 & 1 \\
G2 & Felt disc + diamond paste (Diamond Flex and Diamond excel) & 10 & 1 \\
G3 & Sandpaper discs (Diamond Pro) & 10 & 1 \\
G4 & Silicone tips (DFL polishers) & 10 & 1 \\
\hline
\end{tabular}


Table 3 Composition of the polishing systems

\begin{tabular}{|c|c|c|c|}
\hline Material & Type of presentation & Composition & Manufacturer \\
\hline DFL polishers & Tips & $\begin{array}{l}\text { Stainless steel rods with hard } \\
\text { siliconized rubber tips }\end{array}$ & $\begin{array}{l}\text { DFL, Rio de } \\
\text { Janeiro/RJ, Brazil }\end{array}$ \\
\hline Diamond Flex & Discs & Flexible felt disks & FGM, Joinville/SC, Brazil \\
\hline Diamond Excel & Paste & $\begin{array}{l}\text { Micronized diamond, base lubricant, } \\
\text { thickener and emulsifier }\end{array}$ & FGM, Joinville/SC, Brazil \\
\hline Diamond Pro & Discs & $\begin{array}{l}\text { Disc polyester, adhesive, abrasive, } \\
\text { and silicone rubber }\end{array}$ & FGM, Joinville/SC, Brazil \\
\hline
\end{tabular}

did not have statistically significant differences from each other (Table 4 and Figure 1). There was no statistically significant difference among the groups regarding microhardness (Table 5 and Figure 2).

The observation of surface morphology under SEM showed good agreement with the numerical data of surface roughness. The selected images indicate that groups G1 and G3 (Figures 3 and 4) showed a more smooth and polished surface when compared with groups G2 and G4 (Figures 5 and 6).

\section{Discussion}

Resin composite with larger filler particles are expected to have higher $R_{a}$ values after polishing $[17,18,21]$. Silorane-based resin composites presents filler particles of quartz and yttrium fluoride, which make up $76 \%$ of its weight and which have an average size of $0.47 \mu \mathrm{m}$ and is classified as a microhybrid composite. This lower amount of filler particles with a relatively small size may have contributed to its ability to obtain smaller roughness values $[18,22]$. The values of roughness $\left(R_{a}\right)$ ranged numerically from 0.19 (0.05) to $0.43(0.16) \mu \mathrm{m}$, and in ascending order: Sandpaper discs $(\mathrm{G} 3)<$ Mylar strip (G1) < Felt disc with diamond paste (G2) < Silicone tips (G4).

The filler particles present in a polishing instrument must have higher hardness than the filler particles of the composite resin so that the resin matrix and the particles are both reduced to a higher surface smoothness [21,23]. In this present study, the average roughness $\left(R_{\mathrm{a}}\right)$ of G1 $(0.25 \mu \mathrm{m})$ was statistically equal to G3 $(0.19 \mu \mathrm{m})$, in which sandpaper discs were used with decrescent abrasiveness of coarse, medium, fine and extra-fine. One explanation for the smaller numerical value of G3 is that the Mylar strip could produce some blisters and defects in the composite surface [24]. These irregularities were probably reduced after sanding with \#1200 SiC sandpaper, and the subsequent use of sandpaper disks decreased the surface roughness. Some other studies have shown that sandpaper discs with aluminum oxide particles provide smoother surfaces

Table 4 Description and comparison of surface roughness $\left(R_{a}\right)$ values according to the polishing systems used

\begin{tabular}{lllll}
\hline Groups & \multicolumn{3}{c}{$\mathbf{R}_{\mathbf{a}}(\boldsymbol{\mu m})$} \\
\cline { 2 - 5 } & Min & Max & $(\boldsymbol{s})$ & $\mathbf{p}$ \\
\hline G1 (control) & 0.11 & 0.51 & $0.25(0.14)^{\mathrm{b}}$ & 0.01 \\
G2 (felt disc + paste) & 0.11 & 0.66 & $0.42(0.20)^{\mathrm{a}}$ \\
G3 (sandpaper discs) & 0.11 & 0.29 & $0.19(0.05)^{\mathrm{b}}$ \\
G4 (silicone tips) & 0.21 & 0.71 & $0.43(0.16)^{\mathrm{a}}$ \\
\hline
\end{tabular}

Note: Different letters indicate statistically different means $(p<0.05)$. 


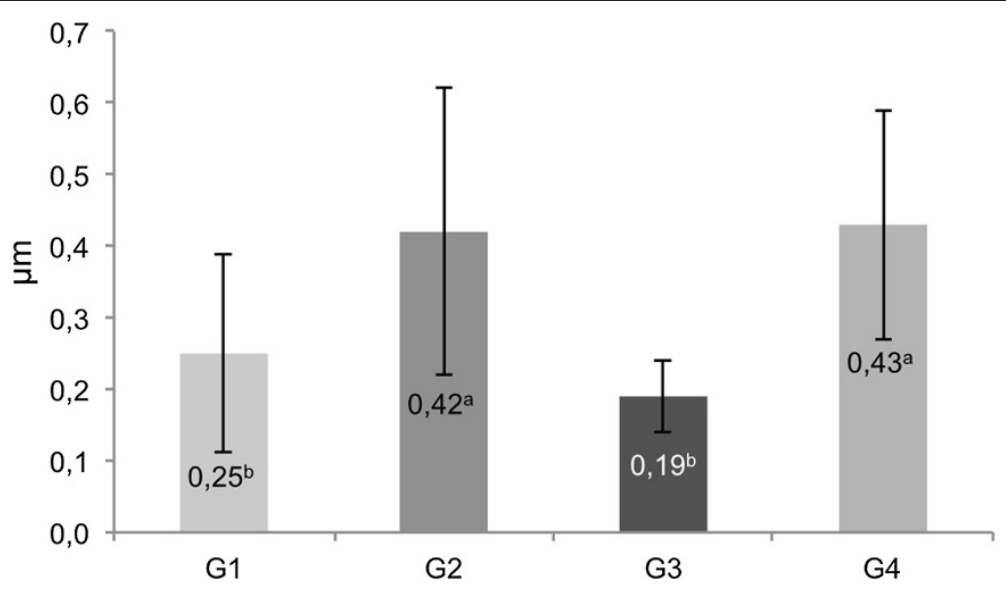

Figure 1 Surface roughness $\left(\mathbf{R}_{\mathrm{a}}\right)$ of each group. Different letters indicate statistically different means $(p<0.05)$.

because they have the ability to erode both the particles and the matrix resin. Çelik et al. (2009) [25], evaluated the effect of sandpaper disks (Sof-Lex Pop-On - 3 M ESPE) compared to silicone polishers (Astropol and Astrobrush - Ivoclar Vivadent) on surface roughness of three flowable resins, and the results reported that sandpaper disks produced a smoother surface the silicone polishers. In the study of Marghalani (2010) [18] the surfarce roughness of silorane-based composites using different polishing systems was evaluated and compared to other composite with different organic matrix. It was observed that the sandpaper disks sequence (Sof-Lex Pop-On - 3 M ESPE) provided the smoothest surface for silorane resin.

The average roughness $\left(R_{a}\right)$ of G2 $(0.42 \mu \mathrm{m})$ was statistically similar to G4 $(0.43 \mu \mathrm{m})$ and significantly higher to $\mathrm{G} 1(0.25 \mu \mathrm{m})$ and $\mathrm{G} 3(0.19 \mu \mathrm{m})$. The polishing paste used in this study is composed of microionized diamonds particles with 2 to 4 microns of grit size. Probably, the G2 group presented higher $R_{a}$ values because the use of felt disc associated to the polishing paste was not capable to reduce both the resin and filler matrixes and resulted in increased surface roughness [15]. This method could be more efficient when applied as the last step of the multiple-step polishing systems [26]. However, a two-step polishing system was used in group G4. Jung, Sehr and Klimek (2007) [27] related that a three-step system was more effective for polishing nanoparticle composites when compared to two- and one step systems, this result was similar to that found by Watanabe, et al. (2005) [21]. Moreover, the silicone polishers may wear the resin matrix and left the filler particles protruding while it also scratches the resin surface [23], and produced a rougher surface in the silorane resin composite. According to Baseren

Table 5 Description and comparison of microhardness (VHN) values according to the polishing systems used

\begin{tabular}{llll}
\hline Groups & \multicolumn{3}{c}{ Microhardness (VHN-49gF) } \\
\cline { 2 - 3 } & Min & Max & (s) \\
\hline G1 (control) & 154.09 & 199.03 & $170.60(15.54)$ \\
G2 (felt disc + paste) & 141.58 & 183.27 & $168.92(13.41)$ \\
G3 (sandpaper discs) & 133.90 & 186.89 & $169.52(15.20)$ \\
G4 (silicone tips) & 157.32 & 182.72 & $170.24(9.27)$ \\
\hline
\end{tabular}




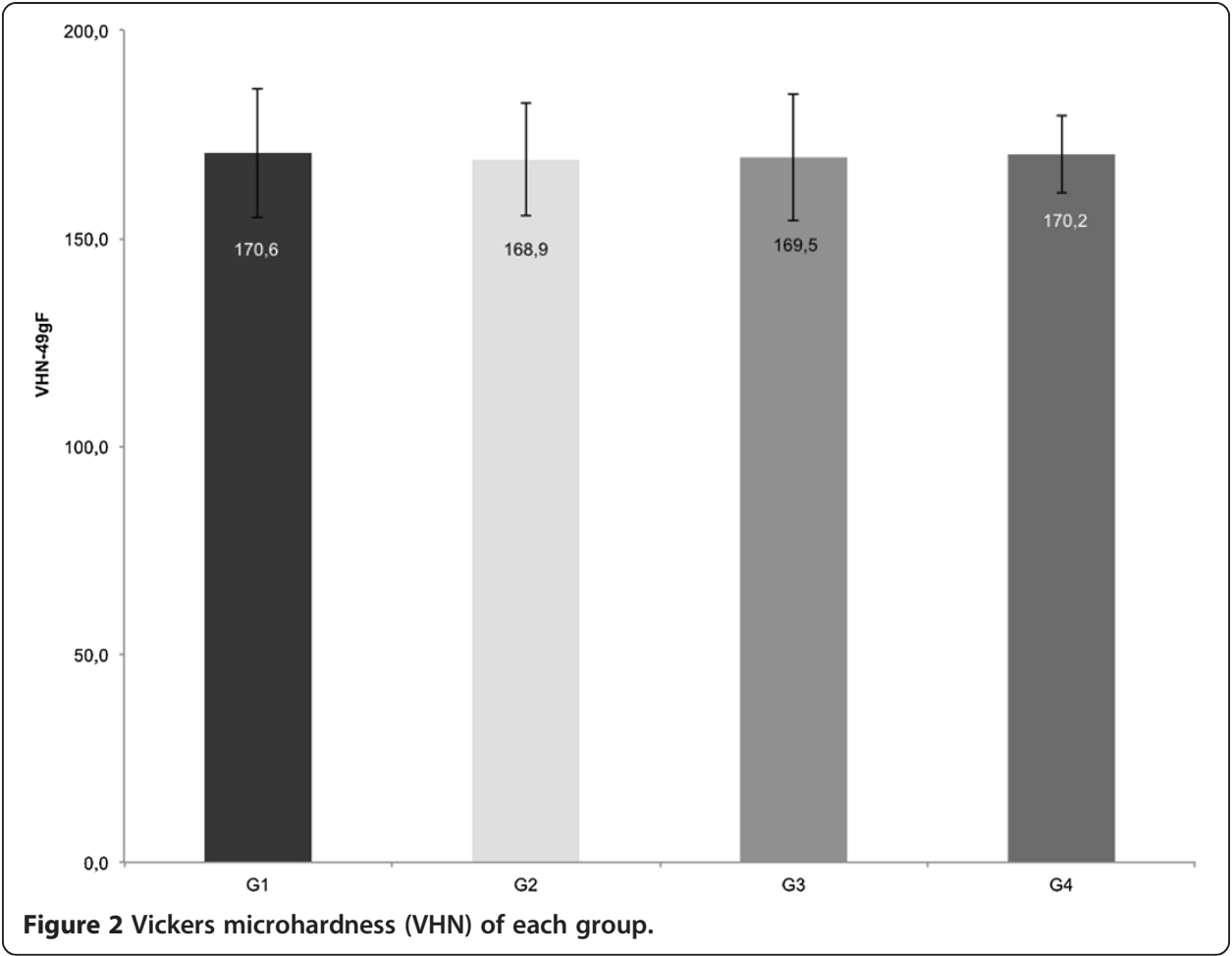

[28] the silicone polishers might be insufficient to polish the surfaces finished with diamond or carbide burs.

Additionally, the use of sandpaper discs in G3 provided an average value that is below the threshold for bacterial adhesion $(0.20 \mu \mathrm{m})$ [29]. This fact implies that certain polishing systems, such as felt disk and diamond paste (G2) and silicone tips (G4), will cause the silorane-based resin composite to be more prone to plaque accumulation, due to the production of greater surface roughness. However, the values obtained with these groups are within the limits of variation of roughness $(0.25$ to

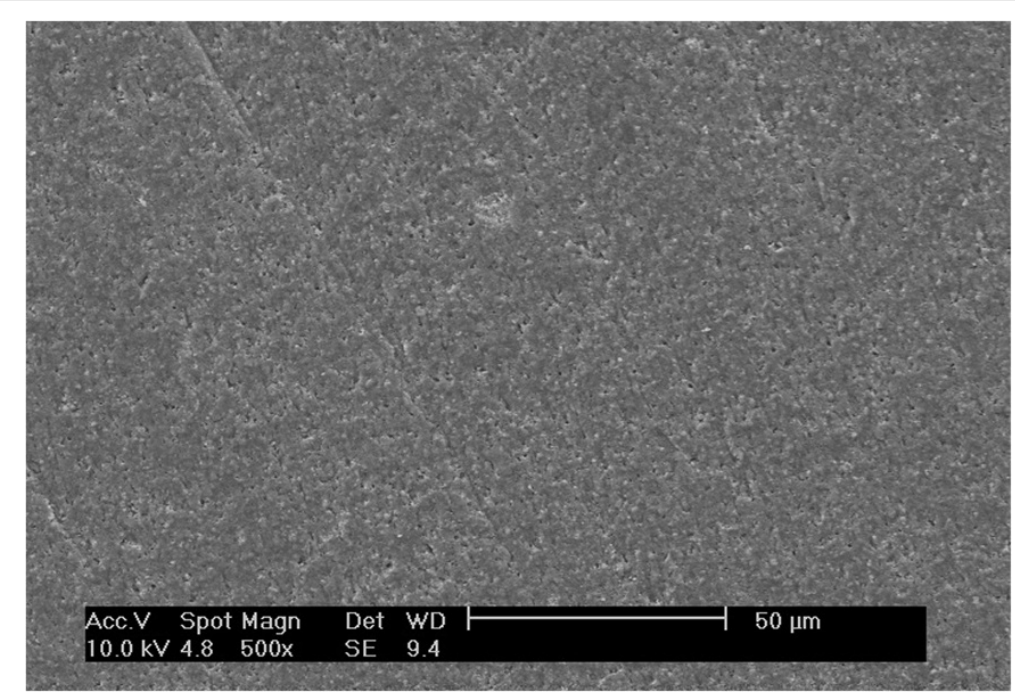

Figure 3 SEM photomicrograph of G1: Filtek P90 composite resin without polishing (control). 


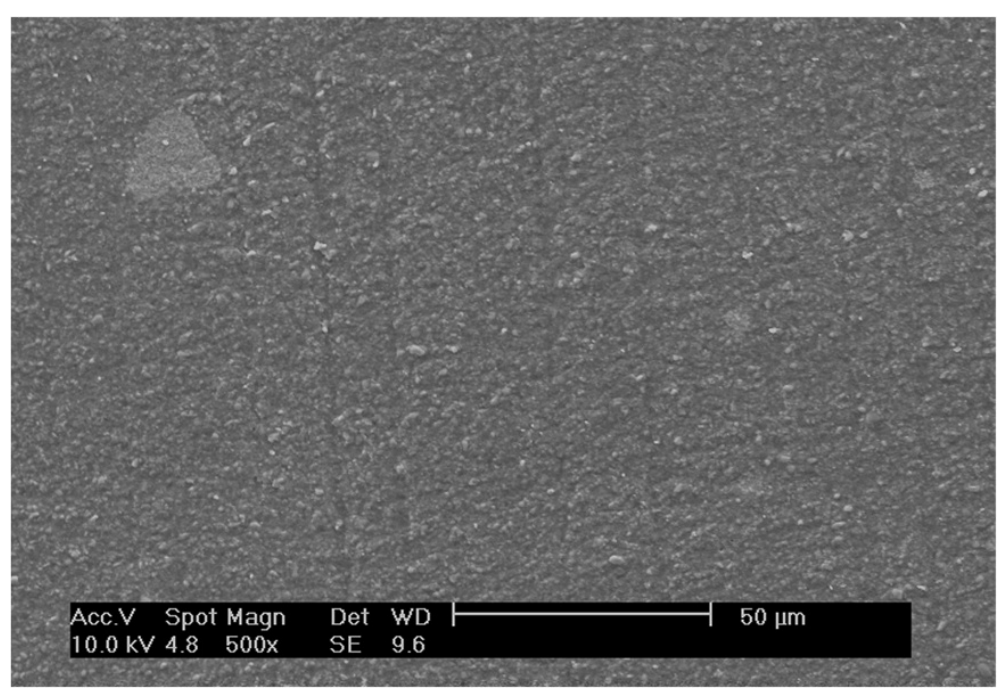

Figure 4 SEM photomicrograph of group G2: Filtek P90 composite resin polished with felt discs and diamond paste.

$0.50 \mu \mathrm{m})$, so indicating that the roughness of the restoration is imperceptible to the human touch [30].

According to Tjan \& Chan (1989) [31], a direct correlation between microhardness and surface roughness was observed, indicating that a material with a higher roughness generally has higher microhardness. This correlation was not observed with the results obtained in this current study, since the microhardness values were statistically similar between groups and only the roughness showed statistically significant differences. Boaro et al. (2013) [32] investigated some physical and mechanical properties of low-shrinkage composites and reported that the silorane-based composite Filtek LS (3 M ESPE) was the only low-shrinkage composite that presented lower shrinkage values compared to conventional composites, but lower degree of conversion as well. The authors stated that this might be due its low shrinkage property.

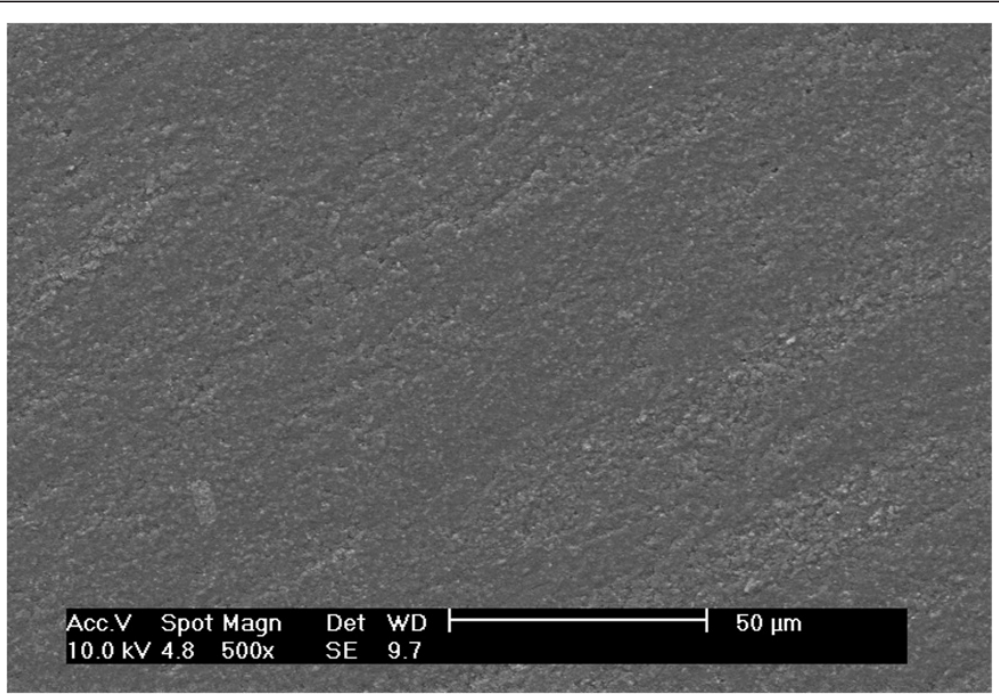

Figure 5 SEM photomicrograph of group G3: Filtek P90 composite resin polished with sandpaper discs of sequential granulation: coarse, medium, fine and extra-fine. 


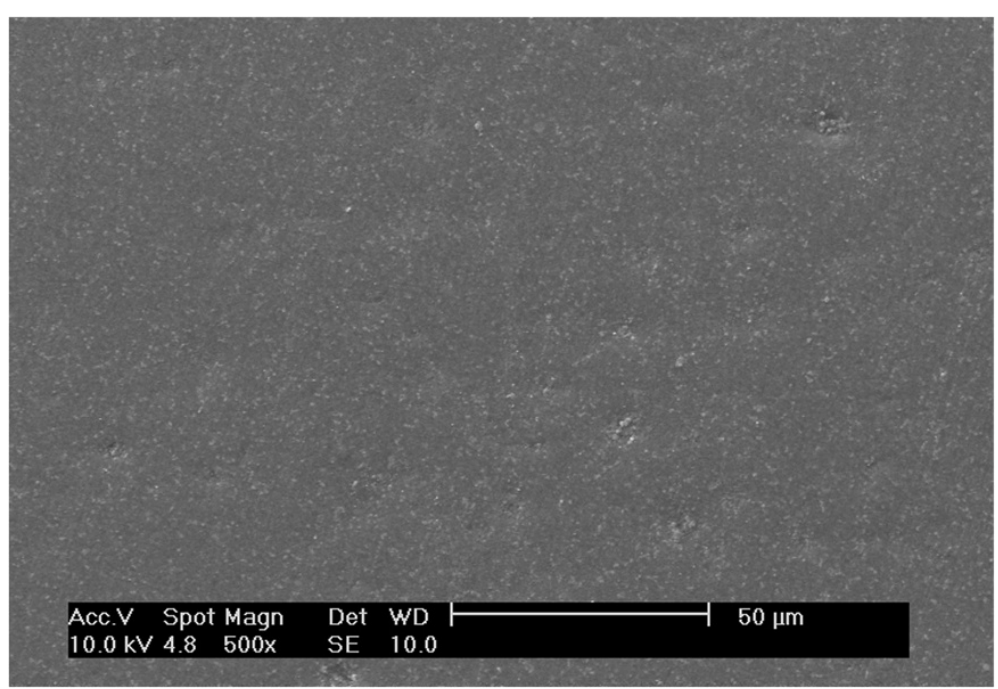

Figure 6 SEM photomicrograph of group G4: Filtek P90 composite resin polished with silicone points.

Different factors influence the polymerization of composite resins, such as light intensity, exposure time and distance between the material and the curing light tip [5,6,33]. D'Alpino et al. (2011) [34] evaluated the influence of energy dose on hardness, polymerization depth and internal adaptation of silorane- and methacrylate-based resins in Class II restorations with different bonding procedures. They related that an energy density of $20 \mathrm{~J} / \mathrm{cm}^{2}$ was found to reduce the formation of internal cracks and increased the hardness of silorane-based composite resin. In this present study, the distance between the curing light tip and the resin composite surface was standardized at $1.1 \mathrm{~mm}$. Caution was taken so that the matrix filling was performed in two increments, with exposure times of $20 \mathrm{~s}$ and a light intensity of $876 \mathrm{~mW} / \mathrm{cm}^{2}$ was produced for each increment. Thus, it can be considered that the polymerization of the composite resin was effective in all specimens.

The Silorane Adhesive System (SAS) is different from the conventional adhesives. The high content of HEMA and water present in the composition of the self-etch primer of SAS makes it more hydrophilic and increases the susceptibility of the hybrid layer to water absorption, which potentially causes degradation and reduces the adhesion durability [35,36]. However, the application of a second hydrophobic layer decreases this permeability and improves the bonding stability [37]. This step could contribute to a thicker hybrid layer [38] which could increase the roughness on the adhesive interface and, probably, the restoration could be more prone to plaque accumulation and, consequently, microleakage.

Further studies are necessary to evaluate the influence of polishing on the physicomechanical properties of the silorane-based composite involving other polishing methods and experimental conditions, such as thermal cycling and different storage media, as well as the comparison of composites with different compositions.

\section{Conclusions}

Within the limitations of this current study: 
- Polishing with felt disc and diamond paste or silicone points significantly increased the surface roughness of a silorane-based resin composite. However, the use of sandpaper discs had no significant influence on surface roughness;

- The different polishing systems did not significantly influence the microhardness of the silorane-based resin composite.

\section{Competing interests}

The authors declare that they have no competing interests.

\section{Authors' contributions}

VCR carried out the laboratory research, drafted the manuscript and performed the manuscript formatting and revision. GRB participated in the laboratory research, carried out the SEM images and contributed to the manuscript formatting and revision. MACA contributed to the laboratory research and the manuscript revision. HPM contributed to the project developing, the laboratory research sequence, the manuscript formatting and revision. All authors read and approved the final manuscript.

\section{Acknowledgments}

The authors thank to 3 M ESPE, FGM and DFL for the kind donation of materials for this study. The authors do not have any financial interest in the materials discussed in this manuscript. Research supported by SEM laboratory of the LCME-UFSC.

\section{Author details}

${ }^{1}$ Department of Dentistry, Federal University of Santa Catarina, Florianópolis, Santa Catarina, Brazil. ${ }^{2}$ Universidade Federal de Santa Catarina, Campus Universitário, Centro de Ciências da Saúde, Departamento de Odontologia, Florianópolis, Santa Catarina 88040-900, Brazil. ${ }^{3}$ Departament of Dentistry, Federal University of Pelotas, Pelotas, Rio Grande do Sul, Brazil. ${ }^{4}$ Universiade Federal de Pelotas, Rua Gonçalves Chaves, 457 - Sala 514 - Centro, Pelotas, Rio Grande do Sul 96015-560, Brazil.

Received: 3 September 2013 Accepted: 2 December 2013

Published: 2 July 2014

\section{References}

1. Weinmann W, Thalacker C, Guggenberger R (2005) Siloranes in dental composites. Dent Mater 21(1):68-74

2. Kopperud HM, Schmidt M, Kleven IS (2010) Elution of substances from a silorane-based dental composite. Eur J Oral Sci 118(1):100-102

3. Bagis $\mathrm{YH}$, Baltacioglu $\mathrm{H}$, Kahyaogullari S (2009) Comparing microleakage and the layering methods of silorane-based resin composite in wide Class II MOD cavities. Oper Dent 34(5):578-585

4. Brandt WC, Lacerda RF, Souza-Junior EJ, Sinhoreti MA (2013) Effect of photoactivation mode on the hardness and bond strength of methacrylate- and Silorane monomer-based composites. J Adhes Dent 15(1):33-39

5. Tchorz JP, Doll R, Wolkewitz M, Hellwig E, Hannig C (2011) Microhardness of composite materials with different organic phases in deep class II cavities: an in vitro study. Oper Dent 36(5):502-511

6. Hooshmand T, Tabari N, Keshvad A (2013) Marginal leakage and microhardness evaluation of low-shrinkage resin-based restorative materials. Gen Dent 61(1):46-50. quiz 51

7. Baracco B, Perdigão J, Cabrera E, Giráldez I, Ceballos L (2012) Clinical evaluation of a low-shrinkage composite in posterior restorations: one-year results. Oper Dent 37(2):117-129

8. Burke FJT, Crisp RJ, James A, Mackenzie L, Pal A, Sands P, et al. (2011) Two year clinical evaluation of a low-shrink resin composite material in UK general dental practices. Dent Mater 27(7):622-630

9. El-Shamy H, Saber MH, Dörfer CE, El-Badrawy W, Loomans BAC (2012) Influence of volumetric shrinkage and curing light intensity on proximal contact tightness of class II resin composite restorations: in vitro study. Oper Dent 37(2):205-210

10. El-Sahn NA, El-Kassas DW, El-Damanhoury HM, Fahmy OM, Gomaa H, Platt JA (2011) Effect of C-factor on microtensile bond strengths of low-shrinkage composites. Oper Dent 36(3):281-292

11. Van Ende A, Mine A, De Munck J, Poitevin A, Van Meerbeek B (2012) Bonding of low-shrinking composites in high C-factor cavities. Journal of Dentistry [Internet]. .. [cited 2012 Feb 3]; Available from: http://www.ncbi.nlm.nih.gov/ pubmed/22273743

12. Kang A, Son S-A, Hur B, Kwon YH, Ro JH, Park J-K (2012) The color stability of silorane- and methacrylate-based resin composites. Dent Mater J 31(5):879-884

13. Krejci I, Lutz F, Boretti R (1999 Jul) Resin composite polishing-filling the gaps. Quintessence Int 30(7):490-495

14. Aykent F, Yondem I, Ozyesil AG, Gunal SK, Avunduk MC, Ozkan S (2010 Apr) Effect of different finishing techniques for restorative materials on surface roughness and bacterial adhesion. J Prosthet Dent 103(4):221-227

15. Jefferies SR (2007) Abrasive finishing and polishing in restorative dentistry: a state-of-the-art review. Dent Clin North Am. 51(2):379-397. ix

16. Yap AUJ, Yap SH, Teo CK, Ng JJ (2004 Jun) Finishing/polishing of composite and compomer restoratives: effectiveness of one-step systems. Oper Dent 29(3):275-279

17. Kakaboura A, Fragouli M, Rahiotis C, Silikas N (2007 Jan) Evaluation of surface characteristics of dental composites using profilometry, scanning electron, atomic force microscopy and gloss-meter. J Mater Sci Mater Med 18(1):155-163

18. Marghalani HY (2010 Apr) Effect of finishing/polishing systems on the surface roughness of novel posterior composites. J Esthet Restor Dent 22(2):127-138 
19. Gordan W, Patel SB, Barrett AA, Shen C (2003 Oct) Effect of surface finishing and storage media on bi-axial flexure strength and microhardness of resin-based composite. Oper Dent 28(5):560-567

20. Flury S, Hayoz S, Peutzfeldt A, Hüsler J, Lussi A (2012 May) Depth of cure of resin composites: is the ISO 4049 method suitable for bulk fill materials? Dent Mater 28(5):521-528

21. Watanabe T, Miyazaki M, Takamizawa T, Kurokawa H, Rikuta A, Ando S (2005 Mar) Influence of polishing duration on surface roughness of resin composites. J Oral Sci 47(1):21-25

22. Ferracane $J \mathrm{~L}(2011 \mathrm{Jan})$ Resin composite-state of the art. Dent Mater 27(1):29-38

23. Reis AF, Giannini M, Lovadino JR, Ambrosano GM (2003 Jan) Effects of various finishing systems on the surface roughness and staining susceptibility of packable composite resins. Dent Mater 19(1):12-18

24. Hachiya Y, Iwaku M, Hosoda H, Fusayama T (1984 Dec) Relation of finish to discoloration of composite resins. J Prosthet Dent 52(6):811-814

25. Çelık EU, Aladağ A, Türkün LŞ, Yilmaz G (2011 Jun) Color changes of dental resin composites before and after polymerization and storage in water. J Esthet Restor Dent 23(3):179-188

26. Da Costa J, Ferracane J, Paravina RD, Mazur RF, Roeder $L$ (2007) The effect of different polishing systems on surface roughness and gloss of various resin composites. J Esthet Restor Dent 19(4):214-224. discussion 225-226

27. Jung M, Sehr K, Klimek J (2007 Feb) Surface texture of four nanofilled and one hybrid composite after finishing. Oper Dent 32(1):45-52

28. Baseren M (2004 Oct 1) Surface Roughness of Nanofill and Nanohybrid Composite Resin and Ormocer-based Tooth-colored Restorative Materials after Several Finishing and Polishing Procedures. J Biomater Appl 19(2):121-134

29. Bollen CM, Lambrechts P, Quirynen M (1997 Jul) Comparison of surface roughness of oral hard materials to the threshold surface roughness for bacterial plaque retention: a review of the literature. Dent Mater 13(4):258-269

30. Jones CS, Billington RW, Pearson GJ (2004 Jan 10) The in vivo perception of roughness of restorations. Br Dent J 196(1):42-45. discussion 31

31. Tjan AH, Chan CA (1989 Feb) The polishability of posterior composites. J Prosthet Dent 61(2):138-146

32. Boaro LC, Gonçalves F, Guimarães TC, Ferracane JL, Pfeifer CS, Braga RR (2013 Apr) Sorption, solubility, shrinkage and mechanical properties of "low-shrinkage" commercial resin composites. Dent Mater 29(4):398-404

33. Stefan-Dogar D, Vandewalle KS (2010 Dec) Photocurability of a new silorane-based restorative material. Gen Dent 58(6):495-502. quiz 503-504

34. D'Alpino PHP, Bechtold J, dos Santos PJ, Alonso RCB, Di Hipólito V, Silikas N, et al. (2011 Nov) Methacrylate- and silorane-based composite restorations: hardness, depth of cure and interfacial gap formation as a function of the energy dose. Dent Mater 27(11):1162-1169

35. Breschi L, Mazzoni A, Ruggeri A, Cadenaro M, Di Lenarda R, De Stefano DE (2008 Jan) Dental adhesion review: aging and stability of the bonded interface. Dent Mater 24(1):90-101

36. Papadogiannis D, Lakes RS, Papadogiannis Y, Tolidis K (2013 Jun) Mechanical viscoelastic behavior of dental adhesives. Dent Mater 29(6):693-701

37. Sauro S, Pashley DH, Mannocci F, Tay FR, Pilecki P, Sherriff M, et al. (2008 Apr) Micropermeability of current self-etching and etch-and-rinse adhesives bonded to deep dentine: a comparison study using a double-staining/ confocal microscopy technique. Eur J Oral Sci 116(2):184-193

38. Santini A, Miletic V (2008) Comparison of the hybrid layer formed by Silorane adhesive, one-step self-etch and etch and rinse systems using confocal micro-Raman spectroscopy and SEM. J Dent 36(9):683-691

doi:10.1186/2196-4351-2-7

Cite this article as: Ruschel et al: Effects of different polishing systems on the surface roughness and

microhardness of a silorane-based composite. Applied Adhesion Science 2014 2:7.

\section{Submit your manuscript to a SpringerOpen ${ }^{\circ}$ journal and benefit from:}

- Convenient online submission

- Rigorous peer review

- Immediate publication on acceptance

- Open access: articles freely available online

- High visibility within the field

- Retaining the copyright to your article

Submit your next manuscript at $>$ springeropen.com 